Article

\title{
Hydrological and Environmental Impact of Wastewater Treatment and Reuse on Zarqa River Basin in Jordan
}

\author{
Naser Almanaseer ${ }^{1, *(0)}$, Muna Hindiyeh ${ }^{2}$ and Raha Al-Assaf ${ }^{3}$ \\ 1 Department of Civil Engineering, Faculty of Engineering, Al-Balqa Applied University, Al-Salt 19117, Jordan \\ 2 Department of Water and Environmental Engineering, Faculty of Engineering, German Jordanian University, \\ Amman 11180, Jordan; muna.hindiyeh@gju.edu.jo \\ 3 Technical University of Vienna, 1040 Vienna, Austria; r_alassaf@yahoo.com \\ * Correspondence: almanaseer@bau.edu.jo
}

Received: 16 October 2019; Accepted: 9 February 2020; Published: 12 February 2020

check for updates

\begin{abstract}
Treated wastewater is an important component of the water resource in Jordan. As Samra wastewater treatment plant—-the largest treatment plant in Jordan—discharges $~ 110$ MCM per year of secondary treated municipal wastewater to Zarqa River, and eventually to Jordan Valley. This research aims at assessing the impact of treated wastewater reuse on the hydrology and environment in the most vulnerable areas within Amman-Zarqa Basin, specifically from As Samra treatment plant to Jerash Bridge. Historical data is collected, field survey is performed, and chemical and biological analyses are performed at eleven selected locations along the study area. Afterwards, all collected data is managed using suitable tools to address the impact. The findings of this research demonstrate high improvement in biological and microbial parameters along the flow path, yet the salinity is increased downstream. It is found that this increase is due to brackish water intrusion, apparently from sandstone aquifer. Analysis of BOD and COD carried out as part of this research showed effective system recovery with COD reduction from $130 \mathrm{mg} / \mathrm{L}$ at the effluent to less than $50 \mathrm{mg} / \mathrm{l}$ in the downstream. Moreover, microbial activities are reduced, mainly due to self-purification in the river.
\end{abstract}

Keywords: hydrology; groundwater; surface water; irrigation; environment; wastewater; Zarqa River; As-Samra treatment plant; farmers; microbial

\section{Introduction}

\subsection{Background}

Water scarcity is dominant in arid and semi-arid regions, resulting in high competition among different sectors such as domestic and agriculture causing a gap between supply and demand. To manage this gap, it is important to understand the root causes of this problem. Classical causes in Jordan include population growth, demographic variables, and infrastructure-related problems. Further, the impact of climate variability and change affects the condition and creates unbalance between surface water and groundwater in spatial and temporal scales [1] Further, population growth, industrialization, irrigation, and other activities accelerated the exhaustion of available resources [2]. To overcome these challenges, adaptive integrated water resources management plan is indispensable. In fact, it has the ability to utilize future forecasts of surface and groundwater resources considering reliable precipitation models [3]. In Jordan, one important nonconventional water resource is treated wastewater. As Jordan is highly dependent on groundwater resources, it is critical that Jordan plan to protect groundwater resources from both reduction and contamination especially in strategic aquifer systems. Values of total coliform and E. Coli observed near Ramtha treatment plant in Northern Jordan 
indicate groundwater contamination. To be specific, total coliform content reach $1600 \mathrm{MPN} / 100 \mathrm{~mL}$, and E. Coli content of $500 \mathrm{MPN} / 100 \mathrm{~mL}$ in groundwater systems in the mentioned area [4].

On the other hand, Jordan is significantly depending on its agricultural sector for ensuring food security at local level, and to export vegetables and other products to Europe and to the Gulf Region. Sustainable agriculture requires soil conservation and demands the application of suitable water for irrigation to avoid salinity [5]. Consequently, Jordan needed to secure adequate water supply for agriculture, specifically in Jordan Valley. For all these consideration, Jordan effectively invested in wastewater treatment and reuse in Azraq Basin (AZB), where treated wastewater is mixed with fresh water of the Zarqa River. The mixed water is collected in King Talal Dam (KTD) and used with other resources for irrigation needed in Jordan Valley [6]. We discuss the impact of treated municipal wastewater reuse in fragile ecosystems, to be specific, in Messolonghion Lagoon and Acheloos Estuary. It describes the planning of the treated wastewater reuse in this ecologically sensitive area, on the basis of the geomorphologic and geotechnical characteristics, climatic factors, and crop irrigation water requirements grown in the area. We found that the municipal wastewater reuse for crop irrigation grown in the protected area appears to be an environmentally acceptable solution for alleviating the natural water shortage. Also, the authors of [7] discuss the optimum transfer factor of heavy metals from soil to plant. The optimum heavy metal transfer factors were found during multiple linear regression analysis, under the effect of treated municipal wastewater. Based on the parameters used in the multiple regression equation, the pollution load index is found to be statistically significant related to transfer factor.

Another aspect of the river environment is the interaction between surface water and groundwater, and the role of climate variability and change in controlling this interaction. Jordan is highly dependent on groundwater with limited availability of surface water.

This research investigates and evaluates the impact of treated wastewater reuse on the environment and on public health in the most vulnerable area within Amman-Zarqa Basin, specifically from As Samra treatment plant to Jerash Bridge. Historical data is collected, field survey is performed, chemical and biological analyses are performed at eleven selected locations, and all data is managed using suitable tools to address the impact. The findings of this research demonstrate high improvement in biological and microbial parameters along the flow path yet the salinity is increased downstream. It is found that this increase is due to brackish water intrusion, apparently from the sandstone aquifer. Analysis of BOD and COD carried out as part of this study showed effective system recovery with COD reduction from $130 \mathrm{mg} / \mathrm{L}$ at the effluent to less than $50 \mathrm{mg} / \mathrm{L}$ in the downstream. Moreover, microbial activities are reduced, mainly due to self-purification in the river. On the other hand, interviews with 27 farmers indicate a considerable reuse of treated wastewater leading to high economic return due to proximity to water and high nutrient load maximizing productivity. Crop analysis is considered to evaluate the impact on public health through contaminants uptake by plants. This analysis showed that the trace elements in the examined crops tend to accumulate in the green matrix through phyto accumulation, and therefore protects fruits. Overall, the outcomes of this research indicate safety of treated wastewater reuse in irrigation practices except for greens. The only concern, however, is the microbial contamination which can be reduced through environmental management and considering survival time of microbes in the environment.

Based on the data collected over the past decade, adoption of wastewater treatment and reuse in AZB clearly helped bridge the gap between supply and demand. Accordingly, decision-makers at the Jordanian Ministry of Water and Irrigation of Jordan (MWI) are considering non-conventional water resources as a feasible option in their water management and development strategies [8,9], shedding some light on the potential environmental implications and the interactions of pharmaceuticals and personal care products PPCPs on the soil for a more effective monitoring of these emerging contaminants in the plants and soil continuum.

The controlled wastewater treatment and reuse is evident in the Jordanian legal documents such as National Water Strategy 2016-2015 [10], Decentralized Waste Water Strategy 2016 [10], and the 
Wastewater Management Policy [11]. Also, Water Authority Law No. 18/1988 amendments 16/1998, 62/2001, state that "wastewater shall not be disposed of; instead, it shall be a part of the water budget". However, in particular areas, the application of treated wastewater may disturb the environment depending on the efficiency of treatment process, and on the water supply system.

As Samra wastewater treatment plant—-the largest treatment plant in Jordan—discharges $~ 110$ MCM per year of secondary treated municipal wastewater to Zarqa River, and eventually to Jordan Valley. A few years after its construction, the efficiency of As Samra started to decrease due different reasons, primarily overloading, and therefore gradual environmental deterioration. In 2008, As Samra was reconstructed and upgraded to enlarge its capacity and enhance effluent quality. Overall, this intervention results in evident improved ecosystem services that needed quantification, which is the focus of this research. In 1985, As Samra wastewater treatment plant was constructed to serve approximately two million people in Amman and Zarqa Governorates [12]. With time, the efficiency of the treatment unit is degraded due to overloads causing clear environmental problems along the river course downstream to Jordan Valley.

In 2008, As Samra wastewater treatment plant was reconstructed and upgraded from stabilization ponds type of treatment to mechanical type, discharging 100 MCM per year of secondary treated wastewater with an average salinity of $900 \mathrm{ppm}$. The quality of the effluents is significantly improved. This improvement in the quality of treated wastewater displays an opportunity toward environmental restoration of the area along Zarqa River. This restoration may enhance the ecosystems along the river and in KTD area, benefitting the farmers, and therefore the agriculture section. Further, this restoration will certainly improve the sanitation and health aspects in the area. For example, after the upgrade of As Samra wastewater treatment plant, the river is carrying more than $100 \mathrm{MCM}$ of continuous flow with improved water quality. As a result, groundwater level within the area is replenished. However, $\sim 20 \%$ of the irrigation water within the study area is shifted from groundwater to treated wastewater due to the availability and quality of treated wastewater. This shift, however, may result in enhanced environmental conditions in terms of soil, groundwater, and the ecosystem in general.

\subsection{Problem Statement}

Due to the shortage of fresh water in semiarid and arid regions, treated municipal wastewater is increasingly used for crop irrigation. In Jordan, where almost all arable land is intensively farmed and water resources are being overutilized, the risk of exposures and adverse health effects from agricultural activities are high. Moreover, the risks are magnified because much of Jordanian farming takes place in close proximity to population centers. This enhances the direct and indirect effects of agriculture on the surrounding municipalities and environmental system including soil, surface and groundwater. In Jordan, $\sim 85 \%$ of the treated wastewater (TWW) is used for crop irrigation; this comprises $\sim 35 \%$ of the total irrigation water $[13,14]$.

\subsection{Research Objectives}

This research utilizes tools to examine the use of treated wastewater along Zarqa River in conjunction with other available water resources by taking into consideration their quantity and quality, in addition to the agronomic, environmental, and economic components. The main objective of this effort is to assess the impact of wastewater treatment and reuse on the environment, including surface water, groundwater, biodiversity, as well as on the public health over selected locations within the study area.

To achieve these two main objectives, a series of methodologies and techniques were adopted to ensure adequate data collection and management, illustrative field and laboratory work, proficient collection and analysis of chemical and biological parameters, inclusive field survey and questionnaire targeting farming practices in the study area, and finally SWOT analysis to conclude solid present and future implications of the wastewater reuse on the environment and public health in the study area. 


\subsection{Study Area}

\subsubsection{Location}

The overall basin (AZB) comprises an area of $\sim 4025 \mathrm{~km}^{2}$, where $89 \%$ is located in Jordan and $11 \%$ inside the Syrian territory. The climate within the basin is ranging from wet to dry. Land use is very diverse as well [15]. To be precise, the focus of this research covers the area from As Samra to KTD (Figure 1).

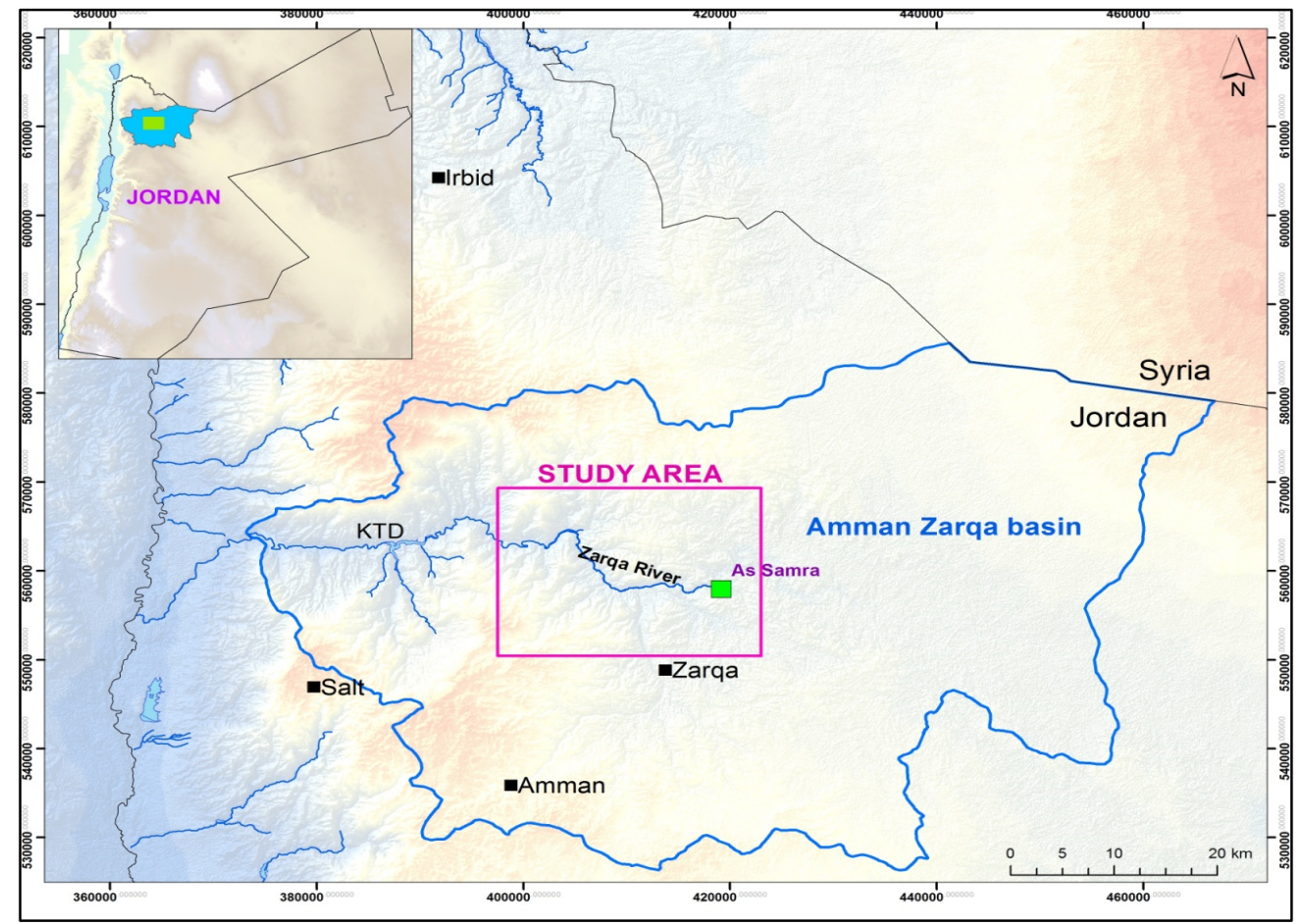

Figure 1. Location of the study area.

\subsubsection{Hydrogeology}

Based on the hydraulic parameters, the Hummar Limestone formation represent the water-bearing layer composing the upper aquifer system with an average thickness of $150 \mathrm{~m}$ with an average saturated thickness of $120 \mathrm{~m}$ as shown in the hydrogeological cross section along the river (Figure 2). The productive Hummar aquifer is a vital aquifer in the river basin used for agricultural and domestic supply for the last 3 years. In the current time the domestic supply was abandoned due to increased salinity and the treated waste water flowing in the river which is in direct interaction with the groundwater system. The Hummar Aquifer is separated from the deep sandstone aquifer by the clay and silt layer of Na'ur marlstone with an average thickness of $100 \mathrm{~m}$.

The Deep Sand Stone Aquifer System known locally as Kurnub sandstone aquifer is not widely invested for water supply due to high salinity that exceeds $2500 \mathrm{mg} / \mathrm{L}$. It is believed that no direct interaction is taking place among the upper and the deep aquifer as the deep aquifer is not under high artesian pressure. Downward leakage is also neglected due to very law hydraulic conductivity of the aquitard unit [16]. 


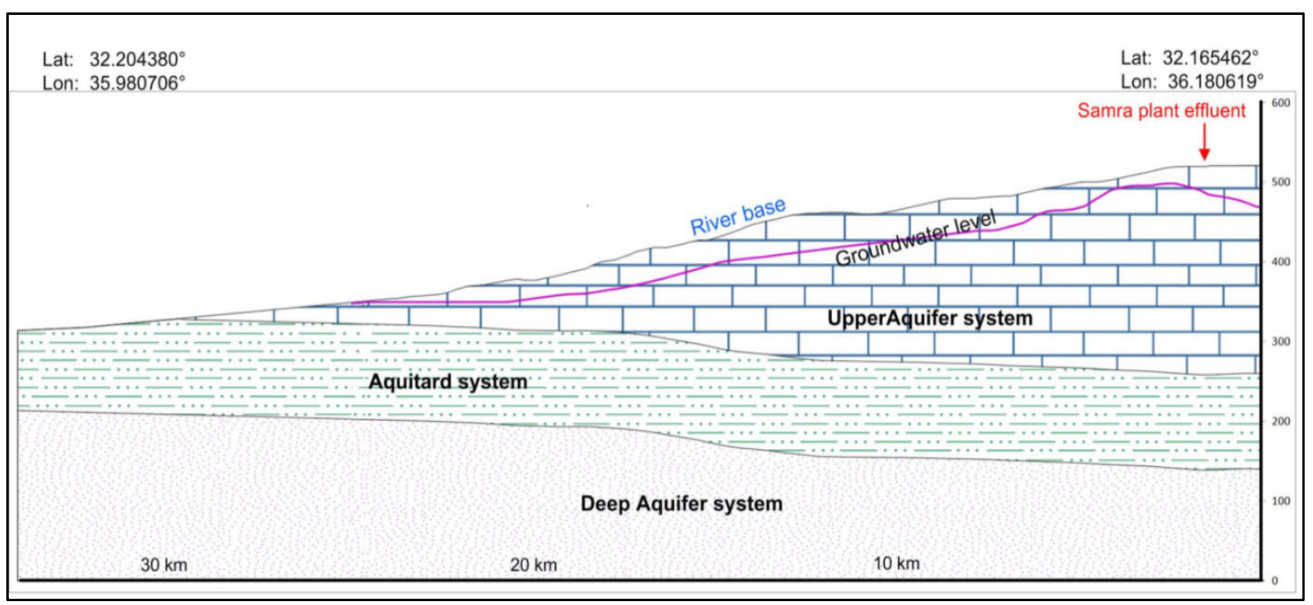

Figure 2. Cross section of Zarqa River.

The sources of groundwater recharge in Amman-Zarqa Basin can be classified into two classes:

- Natural recharge: this type can be categorized as direct recharge (direct infiltration of rainfall) and indirect recharge (which takes place when water percolates to the water table in localized areas through fracture or in areas where the soil cover is very thin or not existing).

- Artificial recharge: this type takes place directly at the point of activities. It includes resources such as irrigation return flow, physical losses, and leakage from water supply networks and effluent of waste water treatment [16]. However [8], groundwater recharge is dominant in the upper Zarqa River (AS Samra plant area). This approach was based on water budget and change of soil storage which is controlled by land use and soil water holding capacity. The resulted natural recharge to the groundwater found to be in the range of 3 to $12 \mathrm{~mm} / \mathrm{year}$, which is largely controlled by rainfall distribution and topographic slope. The spatial distribution of natural recharge is shown in Figure 3.

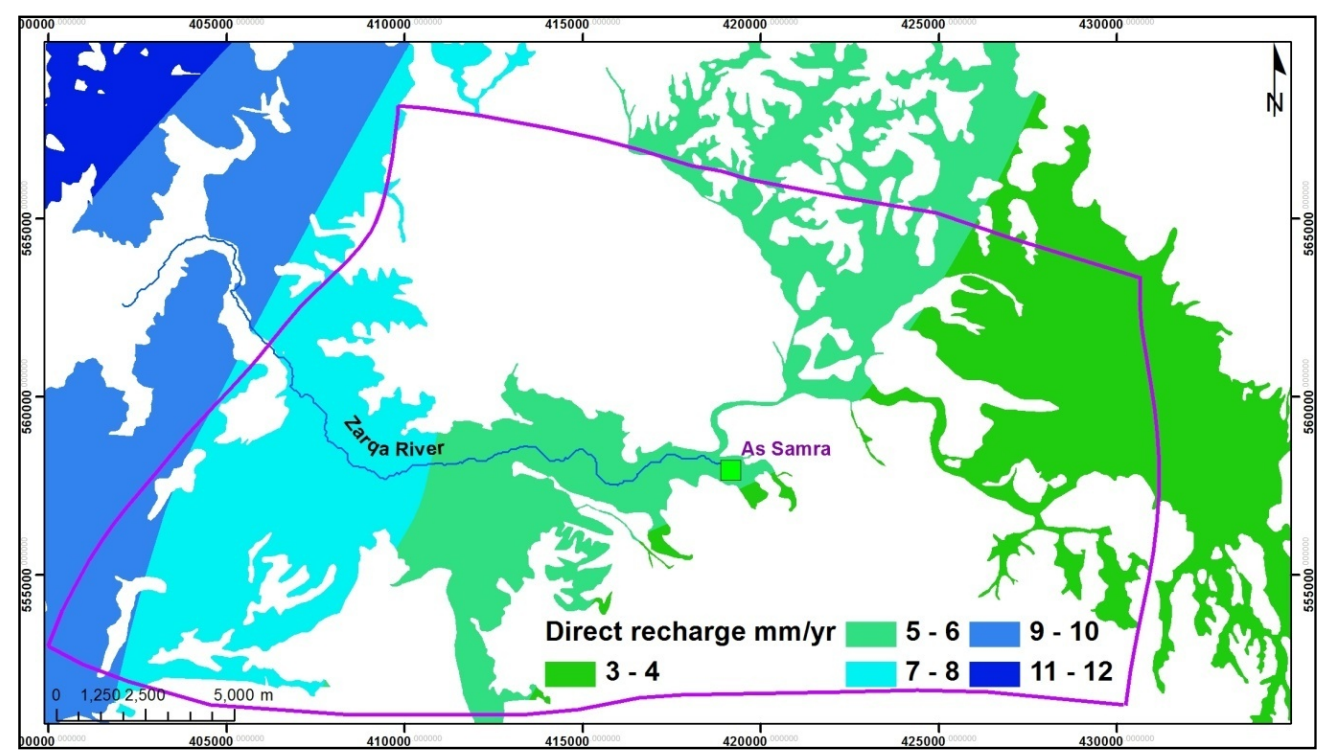

Figure 3. Recharge in the study area.

The hydrology of the study area is controlled by topographic relief, geology, and land use. A number of side intermittent streams discharges to Zarqa River. In general, the drainage system within the study can be described as complex. The catchment area of Zarqa River (Amman Zarqa 
Basin) spreads from the slopes of Jabel Druz to the Jordan River. Zarqa River has the second largest area of drainage basin and mean annual discharge in Jordan. The River comprises two main divisions: Wadi Dhuleil, which drains the eastern part of the catchment area, and Sail Zarqa, which drains the western part. Both meet at Sukhna to form the Zarqa River. As expected, the eastern branch drains only flood flows as a result of precipitation, where the western branch drains flood and base flows [17].

AZB receives an average annual precipitation of $\sim 237 \mathrm{~mm}$. The eastern catchment, which comprises around half of the total catchment area, receives an average amount of precipitation of 182 $\mathrm{mm} /$ year. The western catchment, comprising the highlands and the Jordan Valley area, receives an average precipitation rate of $397 \mathrm{~mm} /$ year. Precipitation over the highlands can occur in the form of snow; in the eastern part of the Basin, it is generally rainfall [17].

Figure 4 shows the long term record of the Zarqa River base flow which indicates the surface-ground water interaction. The discharge into the Zarqa River is resulted from a complicated drainage system governed by topographic relief. According to this record, overpumping and climatic variability reduced the river base flow in the 1970s, which was recovered later on due to the construction of As Samra plant and recovering surface and groundwater resources in the area.

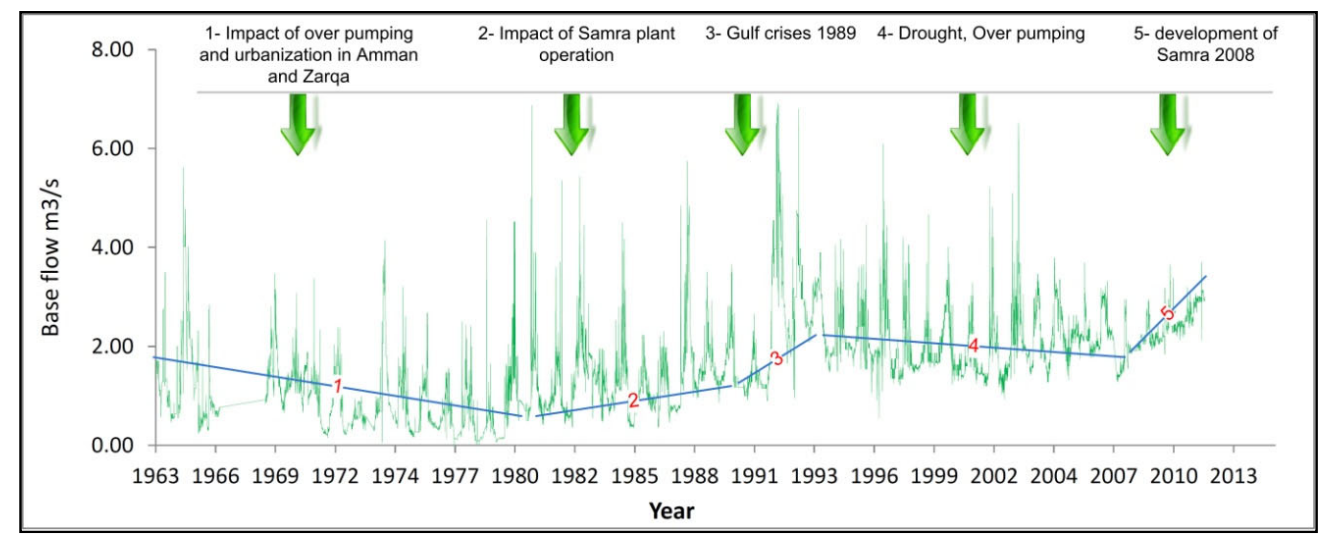

Figure 4. Long-term record of base flow in Zarqa River.

\subsubsection{Wastewater}

In AZB, there are a number of wastewater treatment plants which discharge their effluents directly or indirectly to Zarqa River. The total effluent of treated wastewater in AZB exceeds $120 \mathrm{MCM} / \mathrm{year}$. As Samra plant effluent alone is more than $110 \mathrm{MCM}$ /year. As Samra is the only treatment plant within the study area. As Samra treatment plant was constructed in 1985 near Kherbit As Samra Village. In the period of 1985 to 2008, the notably negative impacts of As Samra effluent were reflected on the water quality of the river, and therefore on the ecosystem. In 2008, As Samra treatment plant was upgraded to mechanical and chemical treatment system therefore the effluent quality was significantly improved. The secondary treated wastewater is discharged along Zarqa River to be mixed in KTD with rainfall water, and released to through the river to a conversion dam near Jordan Valley. From this point, the mixed water is channeled toward Jordan Valley for a second mixing in King Abdullah Canal. The final product is distributed for irrigation along central and southern parts of Jordan Valley.

\section{Materials and Methods}

A cluster of interconnect methods and techniques is utilized to achieve the two main objectives of this study. These methods and techniques include data collection from files and from the field, desktop data management using spreadsheet and ArcMap, laboratory analysis of chemical and biological parameters, laboratory analysis of selected crops, and field survey. Following is a description of these methods and techniques 


\subsection{Data Collection and Management}

All existing data related to the study were collected from different sources. Collected data included data sets on groundwater, surface water, climate, landuse, and soil from the open files of Jordanian Ministry of Water and Irrigation. In addition to that, data were extracted from previous research and reports by researchers and master student. All collected and extracted data were organized in a geospatial data base with geographical locations. Data validation indicated some gaps and missing in the groundwater, climate, and soil data collected from the Jordanian Ministry of Water and Irrigation.

\subsection{Field Survey}

Field survey is carried out to validate the collected existing data and to fill the required data related to water resources, wastewater reuse, conjunctive use, land use, soil, agriculture productivity and practices, potential environmental, and public health issues. To accomplish this, a survey sheet is designed to include list of relevant questions with the focus on two areas: crop type and farmer's practices. The questions are addressed by direct contact with 27 farmers in the study area, and one workshop was organized to have all target groups in one room and extract the needed data. The survey sheet for two categories: crop type and farmer practices with results expressed in percentage are presented in Table 1. Based on the outcomes of this basic field survey, a list of locations is defined for water and plants sampling.

Table 1. Field survey of farmers practices in the study area.

\begin{tabular}{|c|c|c|c|}
\hline Category 1: Crop Type & \multicolumn{3}{|c|}{ Category 2: Farmers Practices } \\
\hline Number of Agricultural Rounds & $\%$ & Irrigation Type & $\%$ \\
\hline 2 Rounds & 41 & Mixed & 9 \\
\hline 1 Rounds & 59 & Flooded & 12 \\
\hline Source of Water & & Sprinklers & 18 \\
\hline Mixed & 22 & Drip & 61 \\
\hline GW & 30 & Fertilizers Use & \\
\hline TWW & 48 & Mixed & 15 \\
\hline Water Mixing Ratio GW:TWW & & Organic & 18 \\
\hline 2 to 1 & 33 & Chemical & 67 \\
\hline 1 to 1 & 67 & Pesticides Use & \\
\hline Is Water Sufficient & & According to help of experts & 15 \\
\hline Yes & 44 & According to farmer knowledge & 85 \\
\hline No & 56 & Calculating Crop Water Demand & \\
\hline Is Water Quality Suitable & & According to help of experts & 6 \\
\hline Yes & 15 & According to farmer knowledge & 94 \\
\hline High salinity & 22 & Water Mixing Ratios to Avoid Salinity & \\
\hline High turbidity & 63 & According to help of experts & 9 \\
\hline Is Soil Quality Suitable & & According to farmer knowledge & 91 \\
\hline Sandy soil & 7 & $\begin{array}{l}\text { Select Crop Type } \\
\end{array}$ & \\
\hline Poor soil & 11 & According to water and soil quality & 6 \\
\hline High salinity & 26 & According to help of experts & 9 \\
\hline Yes & 56 & According to market demand & 21 \\
\hline Crop Type & & According to farmer knowledge & 64 \\
\hline Grapes & 7 & Expert Help and Support & \\
\hline Maize & 7 & Private expert & 12 \\
\hline Citrus & 8 & Agrochemical companies & 12 \\
\hline Alfalfa & 26 & Governmental expert & 15 \\
\hline Olive & 26 & Farmers community & 15 \\
\hline Vegetables & 30 & Self-dependent & 46 \\
\hline Crop Economic Return & & & \\
\hline Very good & 11 & & \\
\hline Fair & 22 & & \\
\hline Low & 26 & & \\
\hline Good & 41 & & \\
\hline Knowledge on Reuse Impacts & & & \\
\hline Yes & 22 & & \\
\hline No & 78 & & \\
\hline
\end{tabular}




\subsection{Water Sampling and Analysis}

Water samples were collected at eleven defined points within the study area along Zarqa River. These eleven points are defined based on exiting data and field survey. The selected points are geographically distributed over a length of approximately $22 \mathrm{~km}$, extended from As Samra treatment plant to Jerash Bridge. The selected points represent As Samra plant effluent, mixing point with Ain Gazal water, springs area, high agricultural return flow spots, and zones with surface water-ground water interaction. The samples were collected by researchers and a master's student.

During this research, three samplings are collected from each point at interval of approximately two months covering late summer and early winter. The samples are analyzed for a number of chemical and biological parameters according to Standard Methods for Examination of Water and Wastewater, 2007. The determined parameters are as follows.

- Total Dissolved Solids (TDS) were measured according to (2540 C. Total Dissolved Solids dried at $\left.180^{\circ} \mathrm{C}\right)$.

- Chemical Oxygen Demands (COD) were measured according to (5220 D. closed reflux colorimetric method).

- $\quad$ BOD and DO were measured according to (4500-O G. Membrane Electrode Method).

- BOD was measured according to (5210 B. 5 days BOD test).

- Total Coliform and E. coli were measured according to (9223 B. Enzyme Substrate Test).

- The $\mathrm{pH}$ and electrical conductivity (EC) were measured by using $\mathrm{pH}$ and EC meters.

- Determination of Soluble Sodium and Potassium were determined by using flame photometer.

- Determination of Soluble Calcium and Magnesium: Calcium titration with EDTA where the Magnesium was determined by (using atomic Absorption).

- Determination of Bicarbonate: The Bicarbonate was determined by titration by $\mathrm{H}_{2} \mathrm{SO}_{4}$.

- Determination of Chloride was done by titration by Silver nitrate $\left(\mathrm{AgNO}_{3}\right)$.

- Heavy metals ( $\mathrm{Cd}, \mathrm{Zn}, \mathrm{Cu}, \mathrm{Fe}$, and $\mathrm{Mn}$ ) were determined by Atomic absorption spectrophotometer.

- Olsen-P was determined by Spectrophotometer.

The findings are documented and tabulated using spreadsheet. Dominant quality parameters are used to determine a list of parameters to be tested in the plants

\subsection{Plant Sampling and Analysis}

Samples from eleven crops were collected in the study area. The plant samples are collected near the eleven water sampling points to relate water quality to plant contaminant uptake level. Samples were analyzed for plant root, leaf, and fruits. Analysis covered microbial contamination (E. Coli) and trace elements. The used methods were drying, digesting then analysis. The samples were prepared as $800 \mathrm{mg}$ plant sample then heated with $10 \mathrm{~mL}$ nitric acid $(70 \%)$, and then the samples were heated another time with $8 \mathrm{~mL}$ Perchloric acid $(70 \%)$. After cooling, $30 \mathrm{~mL}$ of distilled water was added and the resulted $100 \mathrm{~mL}$ sample was analyzed using Inductively Coupled Plasma Mass Spectrometry (ICP-MS). Analyses were done in collaboration with UFZ labs in Germany as part of SMART MOVE and PECTAKE projects funded by BMBF.

\section{Results}

\subsection{Field Survey}

Field survey targets a number of irrigated farms within the study area. The outcomes of the conducted field survey for both crop type and farmer's practices are discussed below. 


\subsubsection{Crop Investigations}

The crop investigations are conducted based on a number of questions. The outcomes of this investigation are summarized in Table 1 . The survey indicates that $41 \%$ of the surveyed farms apply two agricultural rounds of vegetables and cereals, whereas 59\% applies single round of trees such as olives, grapes and citrus. Also, the survey shows that $48 \%$ of the interviewed farmers considered treated wastewater as the only source for irrigation, whereas $30 \%$ use groundwater. On the other hand, some mixing practices were recorded when the water sources are limited, which represents $22 \%$ of the farmers. This, however, can be justified by the high cost of groundwater exploration, high salinity of groundwater, and restricted laws. For water sufficiency, more than $55 \%$ of the farmers stated that water supply is way below the needed amounts. Remarkably, the rest own private groundwater wells that secure the farms. This is due to the growing food market in Jordan, especially in the last two years, as a result of the political situation in the region; most of the farmers intensify agricultural activities in the river basin.

Concerning the water suitability for irrigation from the farmer's point of view, $22 \%$ of farmers highlighted salinity problems in groundwater, and $15 \%$ of farmers reported high turbidity in the river which can affect plant yield and irrigation systems.

Based on the field survey, $26 \%$ of the interviewed farmers reported that they are facing high soil salinity and more water is being used in the washout treatment. Also, poor soil and high sand content were observed in less than $20 \%$.

Within the study area, a variety of crops are present covering a wide spectrum of vegetables, fruit trees, and cereals. It was found that $30 \%$ of the water is reused for vegetables irrigation including but not limited to tomato, cucumber, green pepper, onion, greens, eggplant, and okra. Most of the previous crops are ready for human use without cocking indicating a potential health risk. On the other hand, olive, citrus, and grapes trees farming is being practiced in $\sim 20 \%$ of the total sample and considered as the old practice for local community in the area.

Due to knowledge exchange and development in agricultural practices in the last few years, the economic return for local farmers is enhanced significantly. This is recorded during the field investigation when more than $50 \%$ of the total sample declared a good to very good economic return. The rest, which is less than $50 \%$, are below expectations and with a low economic return because of the traditional practices, low education, and soil-water quality. On the other hand, $\sim 22 \%$ of the famers indicated existing knowledge on the environmental and health impact through different awareness programs took place in the last few years, while the higher percentage with $78 \%$ of the farmers show no previous knowledge on the impacts of such reuse.

\subsubsection{Farmer Practices}

The farmer practices are conducted based on a number of questions and the outcomes are summarized in Table 1. Irrigation is one of the major concerns in agricultural water management due to the complexity of the system in the country and the dependency on different water sources with different qualities. Within the sample, drip irrigation is being practiced over $62 \%$ due to the efficiency of this irrigation type and the affordable cost of drip irrigation lines and connections. Drip irrigation is mainly used for vegetables and some trees, whereas sprinklers are the used technology for alfalfa and field crops with $17 \%$ of the sample. The old technology of flood irrigation is still in practice in some small farms $(12 \%)$ if the farm is very close to the river system and here no pumping is needed.

Agrochemicals are widely used in the area to enhance productivity and reduce risk of diseases and fungal infections. Chemical fertilizers found to be widely used in $67 \%$ of the sample due to low cost and easy use guaranteed solution. Pesticides use is one of the riskiest practices done by farmers, which may affect farmer health, crop quality, and ecosystem components. Lack of help and support to farmers toward the safe use of such chemicals was noticed as 15\% of the sample received support and help by experts to handle such chemicals. When investigating the process guiding the calculation of water requirements for the crops along the Zarqa River system; the expert guidance and follow up, 
which is the most important part in this matter, was almost totally missing, as only $6 \%$ of farmers stated that they are having expert management, whereas $94 \%$ said that they have been doing it according to their personal knowledge, which is not suitable in most cases.

The water extracted from the aquifer has the potential to be mixed with the water coming from Zarqa River which may lead to deteriorate and increase the salinity of the irrigation water and therefore, affect the crops, soil and groundwater in the area. To have a better understanding of the procedures applied by the farmers along the river system, an investigation was varied out to determine how much is the experts contribution in this process; amazingly the results were disappointing as only $9 \%$ of the farmers consult experts in this matter and $91 \%$ of them have been doing it according to their previous knowledge and experience which is not enough in most cases where each crop requires certain values of mixing which leads to the point of the experts guidance in the field of crop selection. As known during the year and with the seasons change; different cropping patterns can be applied over each area along the river system.

Also, it was found that only $9 \%$ of farmers consult experts in order to plant a well guided crop with a previous perspective of the results. Six percent of farmers choose their crops to be planted according to the water and soil quality as they do not want to take any risks. Twenty-one percent determine this process after studying the market and the demand where they can plant demanded crops and get the best benefits, whereas $64 \%$ of farmers choose their crops according to their previous knowledge and experience.

The investigation states that $15 \%$ of the guidance is coming from the farmers local community, $12 \%$ of the total guidance comes from private experts, and agrochemical companies contribute in 12\%, leaving only $15 \%$ of the management and guidance of this important agricultural environment for governmental experts and the self-dependent management dominates with a percent of $46 \%$ leaving us with a potential environmental catastrophe that may occur after some time without guided and well-studied management processes.

\subsection{Water Quality}

Generally, wastewater quality is defined by many parameters and constituents. One of the most important parameters is macro-organic matter, which includes biochemical oxygen demand (BOD) and chemical oxygen demand (COD). BOD is the amount of oxygen that is removed from water during organic matter consumption by bacteria, whereas COD is the amount of oxygen removed from water due to organic matter consumption by chemical matters. Other parameters include micro pollutants, trace elements, microorganisms and pathogeneses, and total dissolved solids (TDS) generated from inorganic soluble salts. Three rounds of water samples were collected at eleven defined points within the study area.

\section{Discussion}

\subsection{Physical Parameters}

Based on field measurements, it was clear that water in the river, which is actually a mix of fresh and treated wastewater, has $\mathrm{pH}$ values ranging from 7.5 to nearly 9 , whereas the turbidity ranges from $\sim 21$ to $\sim 126$ Nephlometric Torpidity Unit (NTU). However, $\mathrm{pH}$ tends to increase toward downstream

\subsection{Major Anions and Cations}

Comparing chemical treated wastewater quality to the Jordanian standards (Water-Reclaimed domestic Wastewater Standard 893/2006) it is concluded that most of the tested samples comply with the reuse standards. Starting by the effluent of Samra plant at S1, we can conclude that the COD is the only parameter that exceeds the standards. Moving downstream some parameters increase due to different factors. The elevated values of parameters can be justified by the illegal practices and 
excessive irrigation. Such practices are clear with the elevated levels of $\mathrm{Na}$ and $\mathrm{Cl}$ while $\mathrm{NO} 3$ is related to fertilizers or contamination by other sources.

Two types of correlation coefficients are used to examine the interrelationships or the dependency between the variables. These two types are as follows.

- Pearson product-moment correlation coefficient, also known as r, R, or Pearson's r, a measure of the strength and direction of the linear relationship between two variables that is defined as the (sample) covariance of the variables divided by the product of their (sample) standard deviations.

- Rank correlation, the study of relationships between rankings of different variables or different rankings of the same variable Spearman's rank correlation coefficient, a measure of how well the relationship between two variables can be described by a monotonic function.

In this research, we adopted Pearson correlation. For example, the chemical constituents of major cations and anions are analyzed. The correlations show strong dependency between $\mathrm{Na}$ and $\mathrm{Cl}$ with $\mathrm{R}^{2}$ about 0.88 . The relation between both $\mathrm{Na}$ and $\mathrm{Cl}$ with TDS is also examined. The analysis shows strong dependency between $\mathrm{Na}$ and $\mathrm{Cl}$, with TDS. This indicates that $\mathrm{Na}$ and $\mathrm{Cl}$ playing strong role in controlling TDS. Therefore, the salinity is dominantly driven by $\mathrm{Na}$ and $\mathrm{Cl}$. Figure 5 demonstrates the correlation between the chemical variables.
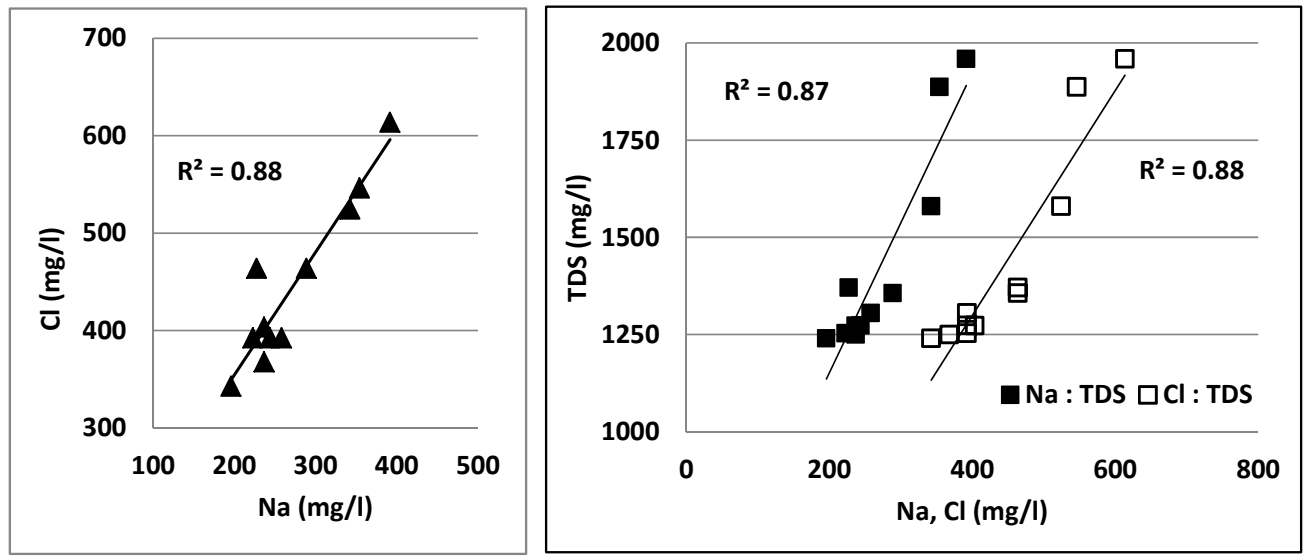

Figure 5. Correlation between $\mathrm{Na}$ and $\mathrm{Cl}$ (left) and $\mathrm{Na}$ and $\mathrm{Cl}$ with TDS (right).

\subsection{Biochemical Parameters}

Three samples from each sampling point are collected and analyzed for a number of biological parameters including BOD and COD correlation analysis among the different variables is carried out to comment on the dependency among the selected variable. Considering historic data from MWI files, the analyses done during this study clearly show that values of both BOD and COD become healthier in 2016 compared to prior 2008. This significant improvement in water quality is due to the upgrade of As Samra implemented in 2008.

On the other hand, the analysis shows that there is strong dependency between Total Coliform and E. Coli. $\mathrm{R}^{2}$ is computed at 0.92 (Figure 6), which is a strong indication of the interdependency of these two variables. Consequently, strong dependency between $\mathrm{BOD}_{5}$ and $\mathrm{COD}$ is clear. $\mathrm{As}^{\mathrm{BOD}_{5}}$ and COD are commonly dependent, and the same applied for Total Coliform and E. Coli, the strong correlation among them indicates reliable data and accurate analysis.

$\mathrm{BOD}_{5}$ and $\mathrm{COD}$ analysis validate the fact that the river environment can be categorized into three distinct zones; decomposition, septic, and recovery. Further, these three zones represent different environments considering dissolved oxygen, pollution loads, and types of aquatic species. COD and $\mathrm{BOD}_{5}$ are generally directly related to dissolve oxygen in any aquatic system. The analysis conducted in this study for COD and BOD is in agreement with this concept. In addition, the analysis shown significant recovery toward the downstream area (Figures 6 and 7) and in agreement with the three 
zones mentioned above. However, field observations suggest that the anomaly in $\mathrm{BOD}_{5}$ and $\mathrm{COD}$ at sampling point number 9 is due to illegal disposal of wastes such as manure, plant remaining, and other sorts of wastes.
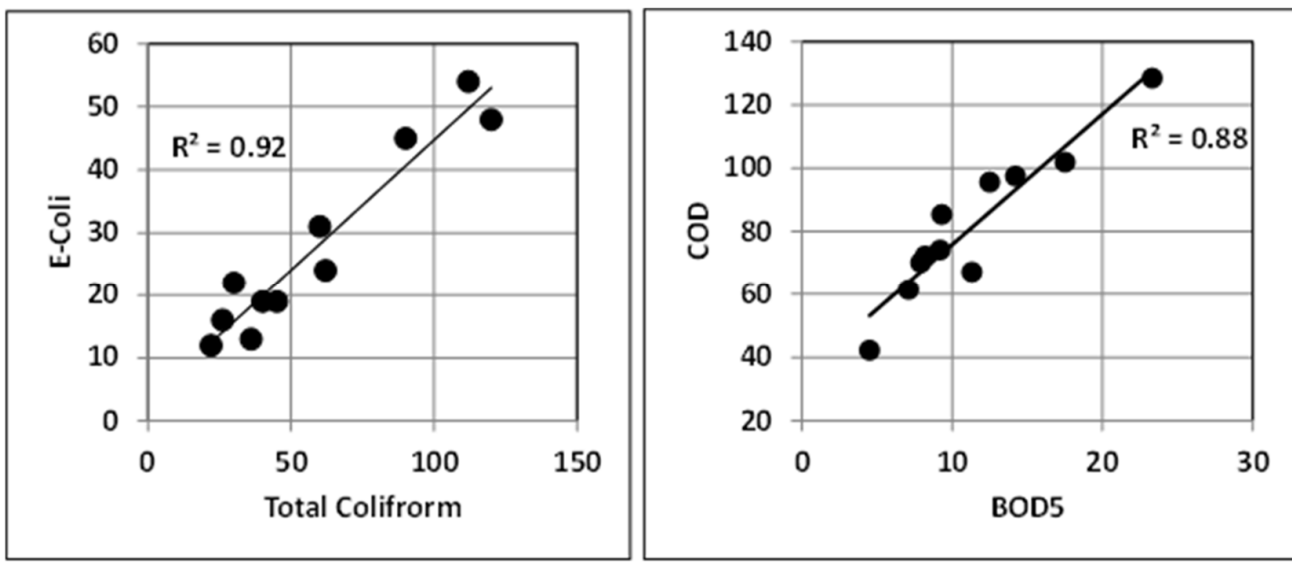

Figure 6. Correlation between total coliform with E-Coli (left) and BOD5 with COD (right).

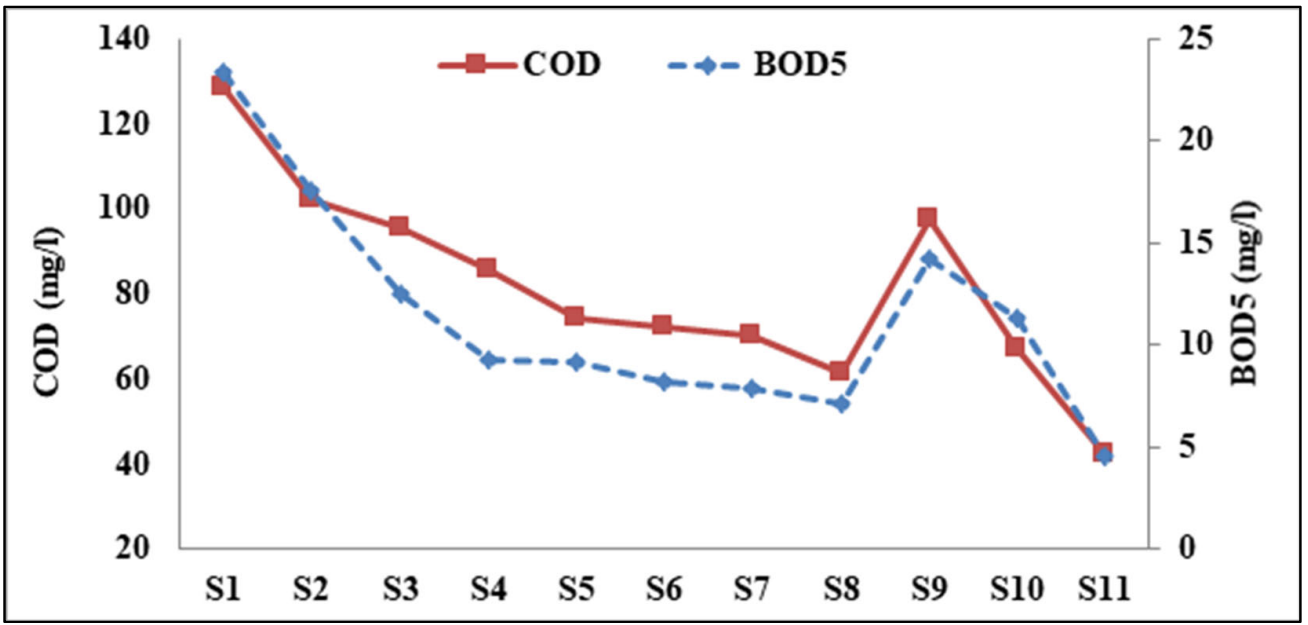

Figure 7. $\mathrm{BOD}_{5}$ and $\mathrm{COD}$ values measured at 11 sampling points in the study area.

\subsection{Groundwater Impact}

Based on the above results, we concluded that the quality of treated water is improved due to the enhanced performance and efficiency of As Samra Treatment Plant. Also, due to natural purification along the river: the analyses of $\mathrm{BOD}_{5}, \mathrm{COD}$, and $\mathrm{DO}$ clearly demonstrated that. Further, this environmental recovery directly boosted agriculture in terms of production and quality. However, it was clear that Electrical Conductivity (EC) is increased in the downstream area. To further assess the impact of treated wastewater on agriculture, we considered EC as one of the indicators, and therefore we examined EC values along the study area. The analysis shows that EC values measured at the 11 sampling points are in the range of approximately 1900-3100 $\mu \mathrm{S} / \mathrm{cm}$. Sampling points 1 through 8 shows EC ranging from 1938 to 2122 with an average of $1987 \mu \mathrm{S} / \mathrm{cm}$. On the other hand, samples collected at points 9-11 showed EC ranging from 2468 to 3060 with an average of $2825 \mu \mathrm{S} / \mathrm{cm}$. The collected data suggests that elevated EC toward the downstream area is not related to the surface water or wastewater treatment process: it is, however, due to upward leakage of brackish groundwater from the sandstone (Kurnub) aquifer (Figure 8). 


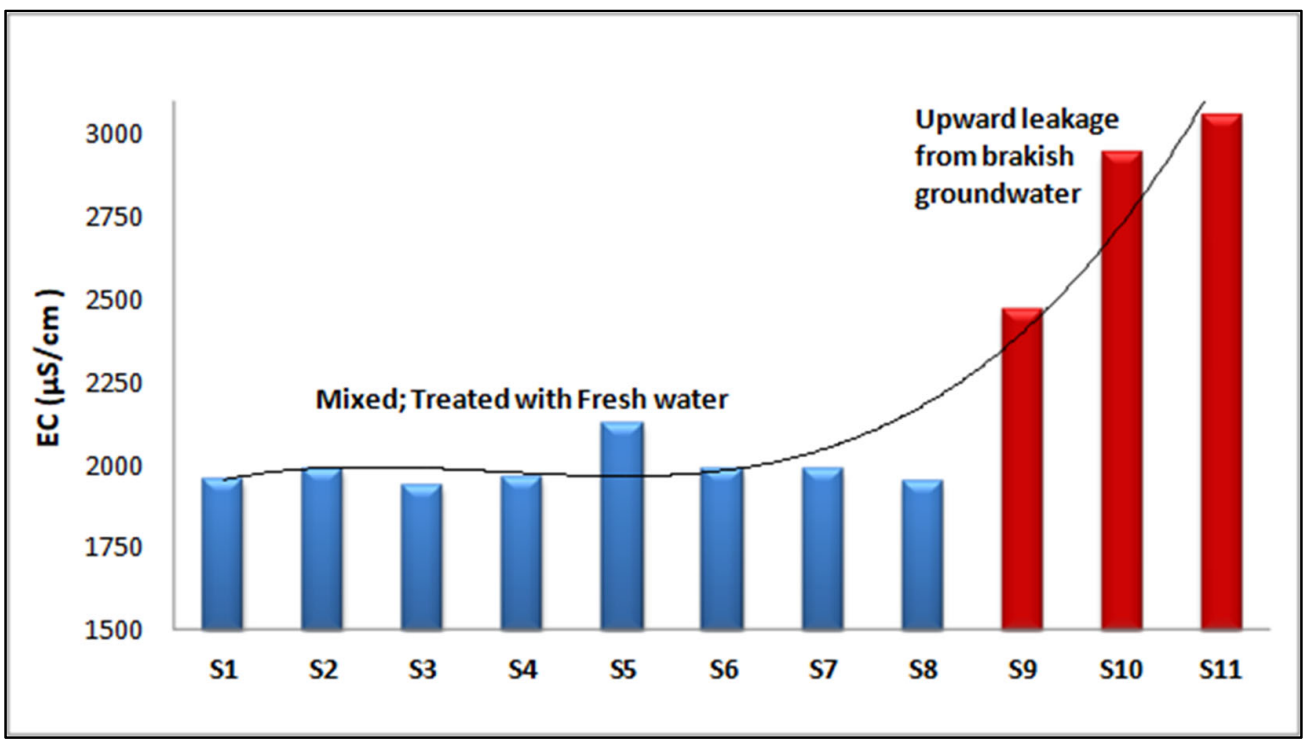

Figure 8. Upward leakage of brackish groundwater from the sandstone (Kurnub) aquifer.

\section{Conclusions}

It is clear that the application of TWW influences Zarqa River system. This influence, however, is varying in space and time, and can impact the ecosystem positively and/or negatively depending on the local conditions.

For groundwater in the study area, the infiltration of TWW that is steadily mixed with surface fresh water increases the quantitative resilience of groundwater system, apparently due to groundwater recharge at the river bed and river banks. On the other hand, the same groundwater recharge lead to unfavorable environmental impacts due to the presence of some chemical and biological constituents, such as heavy metals, pathogens, pharmaceuticals, and other undesirable constituents. Further, the study concluded a gradual increase in surface water salinity toward downstream due to the interaction between surface water and saline groundwater.

For ecosystem, it is clear that TWW flow enhanced regional ecosystem services through formation of additional springs and expansion of vegetation cover. Further, the TWW containing nutrients added into the river improves the environmental conditions of the river results in a healthier ecosystem and amenity. This enhancement however, is resulted in improved agricultural sector and further society resilience.

The data collected demonstrated a strong correlation between BOD5 and COD indicating reliable measurements. Based on these measurements and analysis, the study fully demonstrated that the microbiological content of TWW is decreases toward downstream; this improvement is due to aeration in the river course and resulted in improved water quality. Moreover, samples from the crops are analyzed for fecal coliform E. Coli, and for heavy metals as well. The analysis showed that the E. Coli in irrigation water is much higher than the standards. On the other hand, E. Coli was found to be in the green crops (Rocca, cauliflower, lettuce, and green onion). It was concluded that this variation is due to proximity to soil and high surface area of the plant. Corn and potato reveal no presence of $E$. Coli in the edible parts. For trace elements in irrigation water, the study concluded that there is no trend in the results that can be connected to the distribution of the sampling points.

Author Contributions: Conceptualization, N.A.; M.H.; and R.A.-A. Methodology, N.A. and M.H.; software, N.A. and R.A.-A.; validation, N.A. and M.H.; formal analysis, N.A. and R.A.-A.; investigation, N.A.; M.H.; and R.A.-A.; resources, N.A. and R.A.-A.; data curation, N.A. and R.A.-A.; writing-original draft preparation, N.A. and M.H.; writing-review and editing, N.A.; visualization, R.A.-A.; supervision, N.A. and M.H. All authors have read and agreed to the published version of the manuscript.

Funding: This research received no external funding. 
Acknowledgments: The authors acknowledge the contributions and assistance of Al-Balqa Applied University for providing their laboratories and facilities. The authors thank the University of Jordan for making their laboratory accessible to this research. Special appreciation goes to the farmers within the study area for their great help and interest in this research. Finally, plant samples were analyzed using Inductively Coupled Plasma Mass Spectrometry (ICP-MS). The authors acknowledge that these analyses were done in collaboration with UFZ labs in Germany as part of SMART MOVE and PECTAKE projects funded by BMBF.

Conflicts of Interest: The authors declare no conflicts of interest.

\section{References}

1. Almanaseer, N.; Sankarasubramanian, A. Role of Climate Variability in Modulating the Surface Water and Groundwater Interaction over the Southeast United States. J. Hydrol. Eng. 2012, 17, 1001-1010. [CrossRef]

2. Ta'any, R.A.; Alaween, M.A.; Al-Kuisi, M.M.; Almanaseer, N. GIS based model of groundwater vulnerability and contamination Risk of Wadi Kufrinja catchment area, Jordan. World Appl. Sci. J. 2013, 24, 570-581.

3. Almanaseer, N.; Sankarasubramanian, A. Improving Groundwater Predictions Utilizing Seasonal Precipitation Forecasts from General Circulation Models Forced with Sea Surface Temperature Forecasts. J. Hydrol. Eng. 2014, 19, 87-98. [CrossRef]

4. Tahboub, A.; Ta, R.; Al Ouran, N.; Almanaseer, N.; Azmi, M. Modeling the Transport of Potassium Level in Yarmouk Basin Using SWMS-3D Model. Curr. World Environ. 2014, 9, 646. [CrossRef]

5. Ammari, T.G.; Tahhan, R.; Abubaker, S.; Al-Zu'bi, Y.; Tahboub, A.; Ta'Any, R. Soil salinity changes in the Jordan Valley potentially threaten sustainable irrigated agriculture. Pedosphere 2013, 23, 376-384. [CrossRef]

6. Kalavrouziotis, I.K. Basic Principles of Treated Wastewater Reuse planning in Ecologically Sensitive Areas. Water Air Soil Pollut. 2011, 221, 159-168. [CrossRef]

7. Kalavrouziotis, I.K.; Koukoulakis, P.; Kostakioti, E. Assessment of metal Transfer Factor under irrigation with Treated Municipal Wastewater. Int. J. Agric. Water Manag. 2012, 103, 114-119. [CrossRef]

8. El-Rawy, M.; Zlotnik, V.A.; Al-Raggad, M.; Al-Maktoumi, A.; Kacimov, A.; Abdalla, O. Conjunctive use of groundwater and surface water resources with aquifer recharge by treated wastewater: Evaluation of management scenarios in the Zarqa River Basin, Jordan. Environ. Earth Sci. 2016, 75, 1146. [CrossRef]

9. Papaioannou, D.; Koukoulakis, P.H.; Lambropoulou, D.; Papageorgiou, M.; Kalavrouziotis, I.K. The dynamics of the pharmaceuticals interactive capacity under the effect of artificial enrichment of soil with heavy metals and of wastewater reuse. Sci. Total Environ. 2019, 662, 537-546. [CrossRef] [PubMed]

10. Decentralized Waste Water Strategy; Jordanian Ministry for Water and Irrigation: Amman, Jordan, 2016.

11. Wastewater Production, Treatment, and Use in Jordan; Jordanian Ministry for Water and Irrigation: Amman, Jordan, 2012.

12. Feasibility Study, Environmental and Social Impact Assessment and Detailed Designs and Bidding Documents for Zarqa governorate Wastewater System Reinforcement and Expansion Project; Jordanian Ministry for Water and Irrigation: Amman, Jordan, 2010.

13. Alfarra, A.; Kemp-Benedict, E.; Hötzl, H.; Sader, N.; Sonneveld, B. A framework for wastewater reuse in Jordan: Utilizing a modified wastewater reuse index. Water Resour. Manag. 2011, 25, 1153-1167. [CrossRef]

14. Navon, R.; Hernandez-Ruiz, S.; Chorover, J.; Chefetz, B. Interactions of carbamazepine in soil: Effects of dissolved organic matter. J. Environ. Qual. 2011, 40, 942-948. [CrossRef]

15. Al-Mahamid, J. Integration of water Resources of the Upper Aquifer in Amman-Zarqa Basin Based on Mathematical Modeling and GIS, Jordan. Freib. Online Geol. 2005, 12. [CrossRef]

16. Salameh, E. Water Quality Degradation in Jordan (Impacts on Environment, Economy Generation Resources Base); Friedrich-Ebert-Stiftung and Royal Society for the Conservation of Nature, Higher Council of Science and Technology: Amman, Jordan, 1996.

17. Riemenschneider, C.; Al-Raggad, M.; Moeder, M.; Seiwert, B.; Salameh, E.; Reemtsma, T. Pharmaceuticals, Their Metabolites, and Other Polar Pollutants in Field-Grown Vegetables Irrigated with Treated Municipal Wastewater. J. Agric. Food Chem. 2016, 64, 5784-5792. [CrossRef] [PubMed] 